\title{
Conditions that affect the thresholds of the components of the eyeblink reflex in humans
}

\author{
JN SANES, JA FOSS, JR ISON \\ From the Reflex Laboratory, Department of Psychology, University of Rochester, Rochester, New York, USA
}

SUMMARY The threshold stimulus intensities for elicitation of the two EMG components of the eyeblink reflex were determined in human subjects under different conditions. In the first experiment subjects sat with eyelids open and were not warned about reflex elicitation. The threshold of R1 was substantially greater than that of R2. In four additional experiments subjects (a) triggered the eliciting stimulus, (b) were warned about the arrival of each stimulus, (c) had a conditioning stimulus presented before reflex elicitation, and, (d) had their eyelids closed at the time of stimulus delivery. The conditions of these subsequent experiments reduced the difference between the reflex thresholds largely by lowering the $\mathrm{R} 1$ threshold. These results indicate that variations in the testing environment contribute to the discrepancy between our data showing unequal thresholds for elicitation of the R1 and R2 components and other reports showing equal thresholds. The results are also another illustration of the ability of complex psychological events to selectively affect different reflex pathways.

The reflex eyeblink to a tactile stimulus has two distinct bursts of activity that can be clearly seen in electromyographic (EMG) recordings. ${ }^{12}$ The first component ( $\mathrm{R} 1$ ) is present only on the side of stimulation, with a normal latency of $10-12 \mathrm{~ms}$ and a brief duration of about $5 \mathrm{~ms}$. In contrast, the second component (R2) is bilateral, occurring with equal strength contralateral and ipsilateral to the side of stimulation. The $\mathrm{R} 2$ response also has a longer and more variable latency, of $30-50 \mathrm{~ms}$ depending on stimulus intensity, and a longer and more variable duration of up to $50 \mathrm{~ms}$ or more. The integrity of these responses and changes in their thresholds and amplitude have been useful tools to assess brainstem function. Although the typical report has been that these two reflex components have equal thresholds for elicitation, Ferrari and Messina, ${ }^{3}$ as well as previous investigations from our laboratory, ${ }^{45}$ showed that $\mathbf{R} 2$ had a substantially lower threshold than R1. Since the amplitudes of $R 1$ and $R 2$ are modified by a variety of environmental and physiological conditions, ${ }^{467}$ we suggested that the thresholds of $\mathrm{R} 1$ and R2 also would be affected by differences in the

Address for reprint requests: Dr JN Sanes, Laboratory of Neurophysiology, Bldg 36, Room 2D10, National Institute of Mental Health, Bethesda, Maryland 20205, USA.

Received 7 October 1981 and in revised form 18 December 1981. Accepted 25 January 1982 conditions under which the eyeblink reflexes are elicited.

\section{General methods}

A total of 132 people participated as subjects; all were between 17 and 40 years old and without apparent neurological disorders. The experiments were conducted while the subjects sat inside an electrically isolated and sound attenuated room $(3.7 \mathrm{~m}$ by $2.1 \mathrm{~m}$ by $2.0 \mathrm{~m})$, with an ambient sound level of $27 \mathrm{~dB}(\mathrm{~A})$ re $20 \mu \mathrm{Pa}$. Experimenters and control apparatus were outside the room and subjects were monitored with a closed circuit video system and an intercom. Standard procedures were followed to prepare subjects for EMG recording and for stimulation at the skin surface using Beckman miniature electrodes. Two electrodes for stimulation were fixed with adhesive collars onto the forehead over the right supraorbital branch of the trigeminal nerve and $1 \mathrm{~cm}$ apart. The two electrodes for recording were attached to the skin at the lateral canthus and just ventromedial to this site, over the inferior portion of the orbicularis oculi muscle. A ground electrode was placed midway between the electrodes for stimulation and the electrodes for recording. The impedance between the stimulating electrodes was always less than $5 \mathrm{kohm}$, and the impedances between the recording electrodes and the ground electrode were less than $20 \mathrm{kohm}$.

A Grass SD5 stimulator coupled to a constant current unit (Grass CCU1) provided monopolar square wave stimulus $(0.5 \mathrm{~ms}$ in duration). The EMG recording was fed through an FET preamplifier to a Grass high input impedance differential amplifier (Model 7P5B) with half amplitude settings of $30 \mathrm{~Hz}$ and $3000 \mathrm{~Hz}$. Presence or 
absence of a response was determined by examination of a $100 \mathrm{~ms}$ post-stimulus trace of the EMG recording displayed on a storage oscilloscope. We judged any EMG deflection in excess of twice the background noise as an R1 if it occurred 10-15 ms following a shock, and as an R2 if it occurred $30-80 \mathrm{~ms}$ following a shock. The methods for obtaining reflex thresholds varied from experiment to experiment, because the different experimental conditions required slightly different methods. Subjects were fully informed about the procedures and conditions of the experiments.

\section{Experiment 1}

The purpose of this experiment was to describe the distributions for the sensory cutaneous threshold and R1 and R2 thresholds in a large sample of subjects.

Methods One hundred subjects were observed in this experiment ( 53 females and 47 males), though a full reading of cutaneous, $R 1$, and $R 2$ thresholds were available from only 83 . Thresholds for R1 and R2 were obtained from 89 subjects ( 52 females and 37 males) since 11 did not exhibit any $\mathrm{R} 1$ responses at the highest stimulus intensities that were used. Cutaneous thresholds were not taken on 6 early subjects in this group of 89 . Eliciting stimuli, beginning at $0 \mathrm{~mA}$, were increased in 0.2 or $0.25 \mathrm{~mA}$ steps until the subject reported the presence of the stimulus. This "ascending method of limits" was repeated three times, and the value on the third series was taken as the cutaneous threshold. The stimulation current then was increased in $0.5 \mathrm{~mA}$ increments until a reflex response was observed. The stimulus was repeated at the same intensity until on three successive stimulus presentations the response occurred. If the component failed to occur following an earlier appearance the increments in current were reduced to $0.25 \mathrm{~mA}$. This ascending procedure was continued until the thresholds of both $\mathrm{R} 1$ and $\mathrm{R} 2$ were established or until an intensity of $20 \mathrm{~mA}$ was reached. Stimuli were given at intervals of 15-20 s.

Results The mean cutaneous threshold was $1.3 \mathrm{~mA}$ (SD $=0.5$, range $=0.5-2 \cdot 5 \mathrm{~mA})$. Muscle responses were never observed prior to a subject's report that a stimulus occurred, though in 10 cases the sensory and R2 thresholds were identical. For the other subjects R2 was evoked when the current was increased by a moderate amount. All subjects exhibited R2 responses. For the 89 subjects from which both reflex components were evoked, the mean R2 threshold was $2 \cdot 2 \mathrm{~mA}(\mathrm{SD}=0 \cdot 7$, range $=0 \cdot 6-5 \cdot 0 \mathrm{~mA})$. The $\mathrm{R} 1$ response was never evoked at current intensities lower than the current sufficient to elicit the $\mathrm{R} 2$ response at threshold. The mean $\mathrm{R} 1$ threshold was $7.0 \mathrm{~mA}(\mathrm{SD}=3.5$, range $=3 \cdot 0-18 \cdot 0 \mathrm{~mA}$ ), and the difference between $R 1$ and $\mathrm{R} 2$ thresholds was reliable $(t=14 \cdot 0, \mathrm{df}=88, \mathrm{p}<0 \cdot 01)$. The thresholds for $\mathrm{R} 1$ and $\mathrm{R} 2$ were correlated for women $(r=0.56, p<0.01)$, but not for men $(r=0.28)$. There were differences between men and women for each of the threshold measures: for the cutaneous threshold, $1.2 \mathrm{~mA}$ for women versus $1.6 \mathrm{~mA}$ for men $(t=3.9$, df $=81, \mathrm{p}<$ $0.001)$; for $\mathrm{R} 1,6.0 \mathrm{~mA}$ for women versus $8.4 \mathrm{~mA}$ for men $(t=4.0, \mathrm{df}=87, \mathrm{p}<0.001)$ and for $\mathrm{R} 2,2.0 \mathrm{~mA}$ for women versus $2.4 \mathrm{~mA}$ for men $(t=2.94$, df $=87, \mathrm{p}<$
$0.005)$. The figure illustrates the frequency distributions of the thresholds of R1 and of R2 among the men and women.

These data confirm with a large number of subjects our earlier observations and those of Ferrari and Messina ${ }^{3}$ that $\mathrm{R} 1$ had a considerably higher threshold for elicitation than $\mathrm{R} 2$. The question remains why most other reports concerned with eyeblink reflex thresholds suggested that the two reflex components had identical thresholds. In previous research, ${ }^{458}$ we found that the amplitudes of $\mathrm{R} 1$ and R2 were systematically and differentially affected by a number of conditions that were variously present in other studies. The following experiments examined the effects of each of these conditions on reflex thresholds in turn.

\section{Experiment 2}

When the subject, rather than the experimenter, triggers the eliciting stimulus, the amplitude of $\mathrm{R} 1$ is increased whereas the $\mathrm{R} 2$ is diminished. ${ }^{8}$ The purpose of Experiment 2 was to learn if self-presentation of the eliciting stimulus, a technique sometimes used in the clinic, also could reduce the substantial difference we found between the thresholds of $\mathrm{R} 1$ and $\mathrm{R} 2$.

Methods Thresholds for R1 and R2 were obtained from eight subjects (three females, five males) when either the subject or the experimenter triggered the eliciting stimuli.

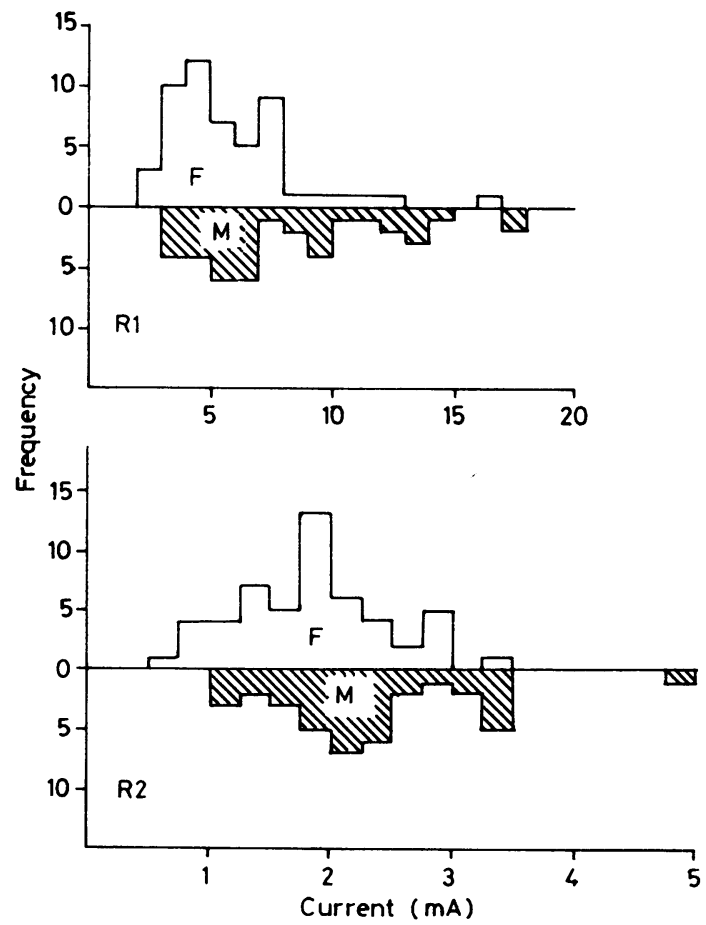

Figure Distributions of the thresholds for elicitation of the $R 1$ and the R2 components of the eyeblink reflex for the female $(F)$ and the male $(M)$ subjects in the first experiment. 
A separate tracking procedure was used to determine the threshold of R1 and R2 for each condition of presentation with the order of the components and conditions randomised across subjects. For a designated reflex component and condition, current intensity was set at $0.5 \mathrm{~mA}$ and raised in $2 \mathrm{~mA}$ steps until that component was evoked. The stimulus intensity was then reduced by $2 \mathrm{~mA}$ and on subsequent trials increased in $1 \mathrm{~mA}$ steps until the component occurred again. The stimulus intensity was then reduced by $1 \mathrm{~mA}$ and then increased, if the component did not occur, or lowered if it did, in $0.5 \mathrm{~mA}$ steps. The tracking procedure was continued until eight reversals had been recorded; the mean of the peaks and troughs for these eight reversals defined the threshold for the designated component. Shocks were delivered $20-40$ seconds apart for both conditions of presentation. For self-presentation trials, a $20 \mathrm{~ms}, 65 \mathrm{~dB}(\mathrm{~A}), 1 \mathrm{kHz}$ tone was presented every $20-40 \mathrm{~s}$ and the subject was instructed to press a button within several seconds of the tone; the stimulus occurred $100 \mathrm{~ms}$ following the press. The button was mounted in a metal cylinder that subjects held in a preferred hand. A background noise of $50 \mathrm{~dB}(\mathrm{~A})$ masked sounds associated with the button press.

Results When the experimenter triggered the reflex eliciting stimulus the mean R2 threshold was $3.5 \mathrm{~mA}$ (SD $=3.3)$ and the mean $\mathrm{R} 1$ threshold was $8.3 \mathrm{~mA}(\mathrm{SD}=4 \cdot 5)$. In contrast, when the subjects triggered the stimulus the mean R2 threshold was $3.2 \mathrm{~mA}(\mathrm{SD}=3.3)$ and the R1 threshold was $4.8 \mathrm{~mA}(\mathrm{SD}=2 \cdot 8)$. The threshold for R1 (F $=18.8, \mathrm{df}=1 / 7, \mathrm{p}<0.01)$ but not for $\mathrm{R} 2(\mathrm{~F}=0.53)$ was reduced when subject triggered the stimulus, compared to when the experimenter had control. Thus, the difference in current intensity between the two thresholds was significantly lowered when the subject delivered the reflex eliciting stimulus $(F=10.7, \mathrm{df}=1 / 7, \mathrm{p}<0.025)$, but even with the method of self-presentation $R 2$ threshold was marginally lower than the $\mathrm{R} 1$ threshold $(F=4 \cdot 09$, df $=$ $1 / 7, \mathrm{p}<0 \cdot 10)$.

\section{Experiment 3}

There are at least two ways to explain the result of the prior experiment, ways which are not mutually exclusive since both could have contributed to the observed effect. Self-presentation of the eliciting stimulus confounds the execution of a motor response with the anticipation of a forthcoming stimulus event. Many experiments have shown that motor responses alter reflex excitability in remote muscles. ${ }^{9-11}$ Others using Pavlovian conditioning demonstrated that a warning signal affects reflex amplitudes. ${ }^{1213}$ In this experiment we separated the factor of anticipation from response execution by varying the occurrence of a warning stimulus prior to reflex elicitation.

Methods Thresholds for R1 and R2 were obtained from eight subjects (three females, five males) who were informed that the reflex eliciting stimulus would occur either after a warning stimulus or without warning. The warning stimulus was a $1 \mathrm{kHz}$ tone at $65 \mathrm{~dB}(\mathrm{~A})$ with a duration of $600 \mathrm{~ms}$; onset of the tone preceded the eliciting stimulus by $500 \mathrm{~ms}$. A background noise of $50 \mathrm{~dB}(\mathrm{~A})$ was continuously present. The thresholds for both R1 and R2 for the warned and unwarned conditions were determined concurrently. A pair of trials, one trial warned and the other unwarned, with the order determined randomly, was presented initially with a stimulus intensity of $1 \mathrm{~mA}$ and then the current was increased in steps of $1 \mathrm{~mA}$ or $0.5 \mathrm{~mA}$ until both the R1 and R2 components occurred in one of the conditions. The trial type in which both $R 1$ and $R 2$ were elicited (it was always the warned condition) was not repeated. For the remaining condition, the reflex eliciting stimulus was delivered at increasing currents until both components were evoked, or until the stimulation current was $2 \mathrm{~mA}$ greater than the intensity at which R1 and R2 were evoked in the other condition of reflex stimulus delivery. Four ascending series of trials were conducted and the mean value of current intensity for the first appearance of each component was taken as the threshold. For seven of the eight subjects on at least one series of trials the threshold of R1 in the unwarned condition differed by more than $2 \mathrm{~mA}$ from the upper threshold in the other condition, so stimulus delivery was stopped before R1 was observed in the unwarned condition. In these series of trials the absent response was given a nominal threshold of $0.5 \mathrm{~mA}$ above the ineffective stimulus intensity at which the series of trials was discontinued.

Results When the reflex stimulus was presented without warning, the R2 threshold was $2.8 \mathrm{~mA}(\mathrm{SD}=0.9)$ and the $\mathrm{R} 1$ threshold was $7.9 \mathrm{~mA}(\mathrm{SD}=2 \cdot 1)$. When the subject was warned about the impending reflex eliciting stimulus, the R2 threshold was $3.3 \mathrm{~mA}(\mathrm{SD}=1.5)$ and the R1 threshold was $5.7 \mathrm{~mA}(\mathrm{SD}=1.9)$. The threshold of $\mathrm{R} 1$ was reliably reduced by warning $(F=116 \cdot 8, \mathrm{df}=1 / 7, \mathrm{p}<$ $0 \cdot 01)$ but that of $R 2$ was not changed $(F=1 \cdot 5)$. The different consequence of the warning stimulus on R1 and R2 was reliable $(F=28.6$, df $=1 / 7, p<0.01)$. In many experimental reports, and certainly in many clinical situations, the subject (patient) and examiner share the same room, allowing ample opportunity for the person being tested to pick up warning cues prior to reflex elicitation. We expect that these unplanned warning stimuli would have the same effect on the threshold of $\mathrm{R} 1$ as the auditory stimuli that were deliberately presented in this experiment.

\section{Experiment 4}

The stimulus conditions of Experiment 3 depended for their effectiveness on the experience of the subject with the stimulus contingencies. However, when a conditioning stimulus precedes an eliciting stimulus by approximately $100 \mathrm{~ms}$, rather than $500 \mathrm{~ms}$, as in the previous experiment, then a form of reflex modification is obtained that does not depend on past experience. ${ }^{14}$ In a previous study, ${ }^{4}$ the amplitude of R1 was enhanced and that of R2 diminished when a brief tone preceded the eliciting stimulus by $100 \mathrm{~ms}$. Here, we examined the influence of the same conditioning stimulus on the thresholds of the two components of the eyelid reflex.

Methods Thresholds for R1 and R2 were obtained from seven subjects (two females, five males). On some trials, the eliciting stimulus was preceded by a brief tone whereas on other trials the eliciting stimulus was presented alone. The $1 \mathrm{kHz}$ conditioning tone was $20 \mathrm{~ms}$ in duration with 5 ms rise and decay times and an intensity of $70 \mathrm{~dB}(\mathrm{~A})$; the 
onset of the tone preceded the eliciting stimulus by $100 \mathrm{~ms}$. Four series of trials were given in a procedure similar to that of the previous experiment. The subjects read magazines during the experimental session.

Results When the tone did not precede the eliciting stimulus the mean $\mathrm{R} 2$ threshold was $2.9 \mathrm{~mA}(\mathrm{SD}=1.8)$ and the mean R1 threshold was $9.9 \mathrm{~mA}(\mathrm{SD}=2.3)$, whereas the mean R2 threshold was $3.7 \mathrm{~mA}(\mathrm{SD}=2.3)$ and the mean $\mathrm{R} 1$ threshold was $8.0 \mathrm{~mA}(\mathrm{SD}=2.7)$ when the tone was presented $100 \mathrm{~ms}$ before reflex elicitation. Delivery of the tone before reflex elicitation decreased the threshold of $\mathrm{R} 1(\mathrm{~F}=33.3$, df $=1 / 6, \mathrm{p}<0.01)$ and increased the threshold of $R 2(F=10 \cdot 1$, df $=1 / 6, p<$ $0 \cdot 025)$. The interaction of $R 1$ versus $R 2$ and tone versus no tone was reliable $(F=68.9$, df $=1 / 6, p<0.01)$. The threshold for R2 was lower than that for R1 in both tone and no tone conditions $(p<0.01)$, but clearly, the difference between the two thresholds was reduced by the preliminary tone. Laboratory and clinical procedures in which the examiner is in direct contact with the subject (or patient) may engender inadvertent lead stimuli at intervals before reflex elicitation that are sufficient to modify reflex amplitudes. The effects of these stimuli can also be responsible for some of the discrepancies concerning R1 and $\mathbf{R} 2$ thresholds.

\section{Experiment 5}

In our experiments on the human eyeblink reflex the subjects sit calmly, typically with their eyelids open. Sometimes they read or are engaged in other tasks. ${ }^{15}$ However, it is common in the literature on the eyeblink reflex to find that the subjects recline and have their eyelids fully or partially closed during the reflex examination. ${ }^{7617}$ This position, especially that of the eyelids, may affect reflex thresholds. When the eyelids are closed the antagonist muscles are relatively quiescent. ${ }^{1819}$ Although the effects of levator palpebrae inactivation on the eyeblink reflex have not been demonstrated, it is reasonable to expect that levator palpebrae relaxation would relieve reciprocal inhibition that, in this case, would tend to enhance excitability of eyeblink reflexes. The release of reciprocal inhibition obtained by relaxed eyelid closure may differentially affect R1 and R2 thresholds, since we know that active and sustained eyelid closure especially facilitates $\mathrm{R} 1$ amplitudes. ${ }^{11}$

Methods Thresholds were obtained from nine subjects (three females, six males). Each subject either sat quietly with eyelids gently closed or with gaze fixed on a white dot, placed about $1 \mathrm{~m}$ in front of the subject's face. The type of trial was signalled by one of two tones, either $1 \mathrm{kHz}$ or 10 $\mathrm{kHz}$, each at $65 \mathrm{~dB}(\mathrm{~A})$ for $20 \mathrm{~ms}$. Eliciting stimuli followed the tones by intervals ranging from 4 to $15 \mathrm{~s}$. Four ascending series were given, using the protocol followed in the last two experiments.

Results When the eyelids were open, the mean R2 threshold was $2.6 \mathrm{~mA}(\mathrm{SD}=1.0)$ and the mean $\mathrm{R} 1$ threshold was $7 \cdot 2 \mathrm{~mA}(\mathrm{SD}=3 \cdot 8)$. When the eyelids were closed, the mean $\mathrm{R} 2$ threshold was $2.3 \mathrm{~mA}(\mathrm{SD}=0.9)$ and the mean $\mathrm{R} 1$ threshold was $5.8 \mathrm{~mA}(\mathrm{SD}=3.2)$. The threshold for $\mathbf{R} 1$ was reliably lower when the eyelids were closed $(F=15.9$, df $=1 / 8, p<0.01)$, whereas the threshold for R2 was not affected by this procedure. This differential effect of eyelid closure was significant $(F=9 \cdot 3$, $\mathrm{df}=1 / 8, \mathrm{p}<0.025)$. Although the difference between the thresholds for R1 and R2 was smaller when the eyelids were closed, the difference between the thresholds in this condition remained considerable $(F=12 \cdot 7, \mathrm{df}=1 / 8, \mathrm{p}<$ $0 \cdot 01$ ).

\section{Discussion}

In these experiments we found that the minimal stimulus sufficient to elicit the $\mathrm{R} 2$ component of the human eyeblink reflex was invariably less than that necessary to elicit the R1 component. This difference was substantial and apparent, although somewhat reduced, across diverse conditions and methods for eliciting eyeblink reflexes. These conditions were asking the subject to trigger the eliciting stimulus (Experiment 2); warning the subject that the stimulus was imminent (Experiment 3); presenting a conditioning stimulus to the subject immediately before reflex elicitation (Experiment 4); and having the subject sit with eyelids closed rather than open when the stimulus was presented (Experiment 5). The summary statistics for all the experiments are in the table. Most often the observed partial convergence of the two threshold values resulted because the procedure lowered the threshold of $\mathrm{R} 1$ without affecting that of R2. Only in Experiment 4, when a conditioning stimulus was presented just prior to the reflex, was the decrement in the $\mathrm{R} 1$ threshold reciprocated by a reliable increase in the threshold value for $\mathbf{R} 2$.

Although reflexive behaviour is conveniently described as the outcome of a "reflection" of its stimulus elicitor through simple neural pathways to the motoneurons, the experiments reported here, and others ${ }^{14}$ indicate that reflex responses are sensitive to events that have no apparent connection to the neural pathways that mediate the reflex except that their onset approximates the reflex's time of activation. The neural mechanisms that mediate reflex modification are not entirely known, but undoubtedly are related to afferent connections and the central pathways internuncial to motoneurons ${ }^{20}$; in this case input to neurons mediating $R 1$ and $R 2$ in the facial motor nucleus ${ }^{21-23}$ and ponto-medullary reticular formation. ${ }^{24} 25$ The general influence of volitional activities, sensory events, and motivational and emotional factors on reflexive behaviour has been known at least since the work of Sechenov. ${ }^{26-28}$ These apparently extraneous factors gain access to the reflex pathways and modify their excitability, with the longer polysynaptic pathways, in our experiments, responsible for $\mathrm{R} 2$, being affected differ- 
Table Mean response thresholds $( \pm 1 S D)$ for $R 1$ and $R 2$ in the "standard conditions" of all five experiments, and in the "reinforced conditions" of self-presentation (Experiment 2); warning stimulus (3); conditioning stimulus (4); and closed eyelids (5)

\begin{tabular}{|c|c|c|c|c|c|}
\hline \multirow[t]{2}{*}{ Experiment } & \multirow[t]{2}{*}{ Number of subjects } & \multicolumn{2}{|c|}{ Standard condition } & \multicolumn{2}{|c|}{ Reinforced condition } \\
\hline & & $R I$ & $R 2$ & $R I$ & $R 2$ \\
\hline $\begin{array}{l}1 \\
2 \\
3 \\
4 \\
5\end{array}$ & $\begin{array}{r}89 \\
8 \\
8 \\
7 \\
9\end{array}$ & $\begin{array}{l}7 \cdot 0 \pm 3 \cdot 5 \\
8 \cdot 3 \pm 4 \cdot 5 \\
7 \cdot 9 \pm 2 \cdot 1 \\
9 \cdot 9 \pm 2 \cdot 3 \\
7 \cdot 2 \pm 3.8\end{array}$ & $\begin{array}{l}2.2 \pm 0.7 \\
3.5 \pm 3.3 \\
2.8 \pm 0.9 \\
2.9 \pm 1.8 \\
2.6 \pm 1.0\end{array}$ & $\begin{array}{l}4 \cdot 8 \pm 2 \cdot 8 \\
5 \cdot 7 \pm 1 \cdot 9 \\
8 \cdot 0 \pm 2 \cdot 7 \\
5 \cdot 8 \pm 3 \cdot 2\end{array}$ & $\begin{array}{l}3.2 \pm 3.3 \\
3.3 \pm 1.5 \\
3.7 \pm 2.3 \\
2.3 \pm 0.9\end{array}$ \\
\hline
\end{tabular}

ently than the short disynaptic pathway responsible for R1. Bowditch and Warren ${ }^{28}$ were so impressed by the degree to which reflexive behaviours were affected by psychological processes that they despaired of obtaining neurological inferences from an examination of reflex behaviours. Their concern was apparently overly cautious. Nonetheless, as Shahani and Young ${ }^{29}$ note, there is more complication to the study of reflexive behaviour than one might suppose. The validity of the inferences to be made about reflex amplitude and threshold does depend on the careful control of extraneous environmental influences.

The discrepancy between our results showing that $\mathrm{R} 2$ had a lower threshold than R1 and the frequent noting that the responses had the same threshold ${ }^{121730-32}$ can probably be attributed to our isolation of the subject from the experimenter and the control apparatus. Similar isolation was described in the other report that the R2 threshold was lower than the R1 threshold. ${ }^{3}$ In situations where the examiner and the subject (or patient) are closeted together, the subject may be warned that the stimulus is about to arrive by some characteristic movement of the examiner, or the subject may detect some apparatus artifact just before reflex elicitation. Then, as in Experiments 3 and 4, we would expect that reflex thresholds would be less disparate than are obtained in conditions of isolation. Although none of our separate procedures caused the two thresholds to be equal (and from no subject in these experiments did an R1 appear at a stimulus intensity inadequate to elicit $R 2$, as Rushworth, ${ }^{2}$ has reported) the effects of these procedures may be additive so that their combination yields similar R1 and R2 thresholds. Additionally, higher rates of stimulus repetition $(0 \cdot 2 \mathrm{~Hz}$ to $1 \mathrm{~Hz})$ have a deleterious effect on R2 amplitudes but facilitate R1 amplitudes. ${ }^{8}$ Stimulus repetition may have similar effects on the threshold measurements of these components. It is noteworthy that Rushworth ${ }^{2}$ was repeating stimuli at $1 \mathrm{~Hz}$ when he described equivalent thresholds for R1 and R2.

Some other differences in methodological detail of the sort not usually described in published accounts may be partially responsible for any remaining discrepancies between our findings and those of others. Our definition of a threshold response was designed to detect small but consistent bursts of activity. It is possible that other investigators have used different criteria for the R1 and the R2 response thresholds, and with these criteria the stimulus levels at threshold are more nearly alike. For example, a smaller "response-time window" for the R2 component would have that effect. When the intensity of the eliciting stimulus is systematically increased we typically observe that the first signs of R2 appear at unusually long latencies, on the order of $60-80 \mathrm{~ms}$. With additional increases in shock intensity, R2 amplitude is enhanced and its latency gets progressively shorter. We have noticed that the first signs of R1 appear when the latency of $\mathrm{R} 2$ is on the order of $30-35 \mathrm{~ms}$. Because of that apparent relationship between R2 latency and R1 strength, if a narrow latency "window" for defining R2 is selected (for example, that the response must occur with a latency no greater than $35-45 \mathrm{~ms}$ ) then the threshold stimulus values for the two components would be more similar than those that we report. Again, however, this redefinition cannot equate the thresholds of the two components. Some individuals have large and rapid reactions yet under our standard eliciting conditions they never exhibit $\mathrm{R} 1$ responses, at least for stimulus intensities below their pain thresholds (which it should be noted, we never exceed).

Our findings have some practical implications. The blink reflex is part of the routine neurological examination because it can reveal gross brainstem dysfunction. The quantitative EMG analysis of the electrically elicited blink is even more revealing because the two components of the blink, which can be discriminated only with electromyographic techniques, reflect activity in different central pathways. ${ }^{33}$ Careful fractionation of $R 1$ and $R 2$ in both sets of palpebral muscles, elicited by stimulating the ipsilateral trigeminal (for both R1 and R2) and contralateral trigeminal (for R2), can illuminate the afferent, efferent, or more central location of brainstem dysfunction. ${ }^{2534}$ In addition, changes of latency 
of the components, especially of $\mathrm{R} 1$, can be useful in the evaluation of demyelinating disease processes. ${ }^{33}$ 35-38 The manoeuvres we describe in this report may be useful when it is otherwise difficult to elicit the reflexes for evaluation. If an $\mathrm{R} 1$ response is difficult to elicit with reasonable levels of stimulation, then it is appropriate to attempt its elicitation in conditions of "reinforcement", for example, by having the patient sit with eyes tightly closed while controlling the stimulus presentation or by pairing the presentation with other warning events. As a corollary, during the examination care must be taken to hold these conditions constant, lest they vary systematically with the test procedures and confuse their issue.

This research was supported by a grant from the United States Public Health Service, ES 01248.

Present address of Dr JN Sanes is: Laboratory of Neurophysiology, Building 36, Room 2D-10, National Institute of Mental Health, Bethesda, Maryland, 20205, USA.

\section{References}

' Kugelberg E. Facial reflexes. Brain 1952;75:385-96.

${ }^{2}$ Rushworth G. Observations on blink reflexes. J Neurol Neurosurg Psychiatry 1962;25:93-108.

${ }^{3}$ Ferrari E, Messina C. Blink reflexes during sleep and wakefullness in man. Electroencephalogr Clin Neurophysiol 1972;32:55-62.

${ }^{4}$ Sanes JN, Ison JR. Conditioning auditory stimuli and the cutaneous eyeblink reflex in humans: Differential effects according to aliosynaptic or polysynaptic central pathways. Electroencephalogr Clin Neurophysiol 1979;47:546-55.

${ }^{5}$ Sanes JN, Ison JR. Modification of brainstem reflex excitability accompanying voluntary activity in humans. Psychophysiology 1980;17:324.

- Kimura J, Harada O. Excitability of the orbicularis oculi reflex in all night sleep: its suppression in non-rapid eye movement and recovery in rapid eye movement sleep. Electroencephalogr Clin Neurophysiol 1972;33:369-77.

${ }^{7}$ Penders CA, Delwaide PJ. Physiologic approach to the human blink reflex. In: Desmedt JE, ed. New Developments in Electromyography and Clinical Neurophysiology, Vol. 3. Basel: Karger, 1973:64957.

${ }^{8}$ Sanes JN, Ison JR, Adelson AA. Reflexogenic and psychogenic reflex modulation: Differential effects according to polysynaptic and oligosynaptic pathways to orbicularis oculi in humans. Neurosci Abstr 1978;4:304.

${ }^{9}$ Kots YM. The Organization of Voluntary Behavior. New York: Plenum Press, 1977.

${ }^{10}$ Pierrot-Deseilligny E, Lacert P. Amplitude and variability of monosynaptic reflexes prior to various voluntary movements in normal and spastic man. In: Desmedt JE, ed. New Developments in Electromyography and Clinical Neurophysiology, Vol. 3. Basel: Karger, 1973:538-49.

${ }^{11}$ Sanes JN. Excitability of cutaneous eyeblink reflexes in humans during organization and performance of voluntary movements. Doctoral dissertation, University of Rochester, 1979.

${ }^{12}$ Ison JR, Sanes JN. Reflex modification by conditional stimuli in human eyelid conditioning. Bull Psychonom Soc 1979;14:239.

${ }^{13}$ Kimble GA, Ost JWP. A conditioned inhibitory process in eyelid conditioning. J Exp Psychol 1961;61:150-6.

${ }^{14}$ Hoffman HS, Ison JR. Reflex modification in the domain of startle: I. Some empirical findings and their implications for how the nervous system processes sensory information. Psychol Rev 1980;87:175-89.

is Ison JR, Ashkenazi B. Effects of a warning stimulus on reflex elicitation and reflex inhibition. Psychophysiology 1980;17:586-91.

${ }^{16}$ Brown WF, Rushworth G. Reflex latency fluctuations on human single motor units. In: Desmedt JE, ed. New Developments in Electromyography and Clinical Neurophysiology, Vol. 3. Basel: Karger, 1973:660-5.

${ }^{17}$ Shahani BT. The human blink reflex. J Neurol Neurosurg Psychiatry 1970;33:792-800.

${ }^{18}$ Allen MW, Blodi FC. Electromyographic study of reciprocal innervation on blinking. Neurology (Minneap) 1962;12:371-7.

${ }^{19}$ Bjork A, Kugelberg E. The electrical activity of the muscles of the eye and eyelid in various positions and during movement. Electroencephologr Clin Neurophysiol 1953;5:595-602.

${ }^{20}$ Leitner DS, Powers AS, Stitt CL, Hoffman, HS. Midbrain reticular formation involvement in the inhibition of acoustic startle. Physiol Behav 1981;26:259-68.

${ }^{21}$ Tanaka T. Pyramidal activation of the facial nucleus of the cat. Brain Res 1976;103:389-93.

${ }^{22}$ McCall RB, Aghajanian GK. Serotonergic facilitation of facial motoneuron excitation. Brain Res 1979;169:11-27.

${ }^{23}$ Panneton WM, Martin GF. Midbrain projections to the trigeminal, facial and hypoglossal nuclei in the oppossum. A study using axonal transport techniques. Brain Res 1979;168:493-511.

${ }^{24}$ Hiraoka M, Shimamura M. Neural mechanisms of the corneal blinking response in cats. Brain Res 1977;125:265-75.

${ }^{25}$ Ongerboer de Visser BW, Kuypers HGJM. Late blink reflex changes in lateral medullary lesions: An electrophysiological and neuroanatomical study of Wallenberg's syndrome. Brain 1978;101:285-94.

${ }^{26}$ Sechenov IM. Reflexes of the Brain (S Belsky, Trans.). MIT Press, Cambridge, Massachusetts, 1965. (Originally published by Sushchinski, St. Petersburg, 1863).

${ }^{27}$ Lombard W. The variations in the normal knee-jerk and their relation to the activity of the central nervous system. Amer J Psychol 1887/1888;1:5-71.

${ }^{28}$ Bowditch HP, Warren JW. The knee-jerk and its physiological modification. $J$ Physiol (Lond) 1890;11:25-64.

${ }^{29}$ Shahani BT, Young RR. Studies of reflex activity from a 
clinical viewpoint. In: Aminoff MJ, ed. Electrodiagnosis in Clinical Neurology. New York: Churchill Livingston, 1980:290-304.

${ }^{30}$ Shahani BT. Effects of sleep on human reflexes with a double component. J Neurol Neurosurg Psychiatry 1968;31:574-9.

${ }^{31}$ Shahani BT, Young RR. Human orbicularis oculi reflexes. Neurology (Minneap) 1972;22:149-54.

${ }^{32}$ Willer JC, Lamour Y. Electrophysiological evidence for a faciofacial reflex in facial muscles in man. Brain Res 1977;119:459-64.

${ }^{33}$ Kimura J. Electrically elicited blink reflex in diagnosis of multiple sclerosis. Review of 260 patients over a seven year period. Brain 1975;98:413-6.

${ }^{34}$ Kimura J, Lyon LW. Orbicularis oculi reflex in the Wallenberg syndrome: Alteration of the late reflex by lesions of the spinal tract and nucleus of the trigeminal nerve. J Neurol Neurosurg Psychiatry 1972;35:22833.

${ }^{35}$ Kimura J. Alteration of the orbicularis oculi reflex by pontine lesions: Study of multiple sclerosis. Arch Neurol 1970;22:156-61.

${ }^{36}$ Kimura J. The blink reflex as a test for brainstem and higher central nervous system function. In: Desmedt $\mathrm{JE}$, ed. New Developments in Electromyography and Clinical Neurophysiology, Vol. 3. Basel: Karger, 1973:682-91.

${ }^{37}$ Lyon LW, Van Allen MW. Orbicularis oculi reflex: Studies in internuclear ophthalmoplegia and pseudointernuclear ophthalmoplegia. Arch Ophthal 1972;87:148-54.

${ }^{38}$ Namerow NS. Observations of the blink reflex in multiple sclerosis. In: Desmedt JE, ed. New Developments in Electromyography and Clinical Neurophysiology, Vol. 3. Basel: Karger, 1973:692-6. 